\title{
DAYA DUKUNG JASA EKOSISTEM PENYEDIA AIR DAN PANGAN DI KAWASAN HUTAN TUWANWOWI KABUPATEN MANOKWARI
}

\section{(Carrying Capacity of Ecosystem Services for Water and Food around Tuwanwowi Forest Area of Manokwari)}

\author{
SANDONA H.L. KUWEI ${ }^{1}$, JONNI MARWA $^{1} \bowtie$ ALEXANDER RUMATORA $^{1}$ \\ ${ }^{1}$ Program Studi Kehutanan, Fakultas Kehutanan Universitas Papua Manokwari, Papua Barat, 98314. \\ Tlp/Fax: +62986211065. \\ $\square$ Penulis Korespondensi: Email: jonnimarwa@gmail.com \\ Diterima: 04 Okt 2020| Disetujui:08 Nov 2020
}

\begin{abstract}
Abstrak. Penelitian ini bertujuan untuk mengetahui kondisi ekosistem hutan di kawasan Tuwanwowi guna mendukung jasa ekosistem sebagai penyedia air dan sumber pangan bagi kehidupan masyarakat disekitarnya. Metode yang digunakan yaitu metode kuantitatif dan teknik wawancara guna menghimpun informasi. Analisis ketersediaan air dilakukan dengan menggunakan metode koefisien limpasan, sementara identifikasi status daya dukung lahan dilakukan dengan membandingkan SL dan DL dari hasil perhitungan. Hasil penelitian memperlihatkan bahwa ketersediaan lahan (SL) sebesar $1.568,8$ ha sedangkan nilai kebutuhan lahan (DL) adalah 35,442 ha yang berarti nilai $\mathrm{SL}<\mathrm{DL}$ dan daya dukung lahan dinyatakan surplus atau melimpah. ketersediaan air $\left(\mathrm{S}_{\mathrm{A}}\right)$ yang tersimpan mencapai 48.621.821,78 $\mathrm{m}^{3} /$ tahun dan kebutuhan air $\left(\mathrm{DA}_{\mathrm{A}}\right)$ sebesar $7.241,8$ jiwa $\mathrm{m}^{3} /$ tahun yang mana mengindikasikan bahwa kebutuhan akan lahan di kampung Somi dan Wasai lebih kecil dari ketersediaan lahan.
\end{abstract}

Kata kunci: Limpasan, ketersedian air, daya dukung, jasa ekosistem, surplus, defisit

\begin{abstract}
This study has been focusing on understanding forest ecosystem condition in Tuwanwowi area in order to underpin the availability of water and food for the forest for local inhabitants around the area. Quantitative approach has been implemented for analyzing water and land carrying capability. Water availability analysis was carried out by applying runoff coefficient method, while for identifying land use carrying capacity, the comparison from quantitative analysis result was undertaken for SL (land availability) and DL (land needed). The result noticed that land availability (SL) was 1,568.8 ha, at the meantime, land that has been needed around 35.442 ha which means SL < $D L$, thus land carrying capacity was surplus or available. In addition to the water availability $\left(S_{A}\right)$, it has been pointed out around 48,621,821.78 $\mathrm{m}^{3} /$ year and the necessity (DA) was 7,241.8 jiwa $\mathrm{m}^{3} /$ year which was designated a low frequency in terms of land use in daily activity from both villages, Somi dan Wasai.
\end{abstract}

Keywords: Runoff, water availability, carrying capacity, ecosystem service, surplus, deficit

\section{PENDAHULUAN}

Menurut UU Nomor 32 tahun 2009 tentang Pengelolaan Lingkungan Hidup, daya dukung lingkungan hidup diartikan sebagai kemampuan lingkungan hidup untuk mendukung peri kehidupan manusia dan makhluk hidup lain. Soemarwoto (1983) mendefinisikan daya dukung lahan merupakan kemampuan suatu lingkungan untuk mendukung lingkungan kehidupan, untuk daya dukung lahan pada 
dasarnya bergantung pada persentasi lahan yang dapat dipakai untuk lahan pertanian dan hasil pertanian persatuan luas dan waktu. Peraturan Menteri Negara Lingkungan Hidup (Permen LH) Nomor 17 Tahun 2009 pasal 1, menyebutkan bahwa daya dukung lingkungan hidup adalah kemampuan lingkungan hidup untuk mendukung perikehidupan manusia dan mahkluk hidup lain (Peraturan Menteri Lingkungan Hidup 2009). Seluruh aktivitas manusia dalam memenuhi kebutuhan hidupnya selalu membutuhkan wadah/ruang, sehingga ketersediaan lahan sangat besar pengaruhnya terhadap aktivitas manusia.

Penentuan daya dukung lingkungan hidup dilakukan berdasarkan tiga pendekatan, salah satunya dengan pendekatan perbandingan antara ketersediaan dan kebutuhan air. Air merupakan sala satu unsur alam yang sangat penting dalam kebutuhan keberlangsungan makluk hidup kuhsusnya pada manusia. Satatus daya dukug lingkungan dengan pendekatan air menunjukan suatu kondisi ketersediaan air dengan kebutuhan yang ada ketika ketersediaan air tahunan tiap orang jatu dibawa $500 \mathrm{~m}^{3}$, muncul ancaman terhadap kepentingan kehidupan masyarakat (Shiva 2002). Segala upaya dilakukan selama ini oleh pemerintah untuk memenuhi kebutuhan pangan beras bagi masyarakat untuk meningkatkan produksi padi. Pada dasarnya masyarakat Indonesia mengkonsumsi pangan lokal yang berasal dari hutan (Cabuy et al. 2012), namun saat ini pola hidup masyarakat Indonesia terus berubah dimana masyarakat yang sebelumnya mengkonsumsi non beras berubah menjadi beras. Selain itu, besar jumlah penduduk juga akan sangat menentukan kemampuan wilayah tersebut untuk mendukung aktivitas penduduknya, sehingga memperoleh suatu standar hidup yang layak (Bratakusumah dkk. 2005). Hal ini juga yang terjadi di Manokwari sebagai ibu kota dari Provinsi Papua Barat, dimana terjadi pertambahan penduduk setiap tahun. Berdasarkan informasi Badan Pusat Statistik (BPS) Kabupaten Manokwari, penduduk Manokwari tahun 2005 berjumlah 108.051 jiwa, tahun 2014 naik menjadi 154.296 jiwa, sedangkan tahun 2018 naik lagi hingga mencapai $\quad 173.020 \quad$ jiwa (https://manokwarikab.bps.go.id).

Salah satu kawasan di kabupaten Manokwari yang mengalami tekanan perubahan adalah kawasan hutan Tuwanwouwi akibat pembangunan maupun meningkatnya jumlah penduduk. Hutan Tuwanwowi ditunjuk menjadi hutan Pendidikan Tuwanwowi berdasarkan Surat Keputusan Menteri Kehutanan Nomor: 423/Kpts-11/87 tanggal 28 Desember 1987 tentang Penunjukan Kawasan Hutan Tuwanwowi seluas \pm 6000 Ha yang terletak di Kabupaten Dati II Manokwari, Propinsi Dati I Irian Jaya sebagai Kawasan Hutan Pendidikan dan Latihan Kehutanan Manokwari. Dengan demikian tujuan dari penelitian adalah untuk mengetahui berapa luas tutupan hutan dan lahan kawasan hutan Tuwanwowi yang mampu mendukung penyediaan air dan pangan.

\section{METODE PENELITIAN}

Penelitian ini dilaksanakan di kawasan Hutan Tuwanwowi Distrik Manokwari Selatan Kabupaten Manokwari dan waktu pelaksanaan selama \pm 2 minggu dimulai dari tanggal 18 Juni sampai tanggal 29 Juni Tahun 2020.

\section{Metode dan Teknik}

Metode yang digunakan dalam penelitian ini yakni metode kuantitatif dengan teknik survei dan wawancara semi struktural.

\section{Variabel Penelitian}

Variabel yang dapat diamati dalam penelitian ini adalah daya dukung Jasa ekosistem air dan pangan serta proyeksi penduduk dan daya dukung Jasa ekosistem air dan pangan. 


\section{Pelaksanaan Penelitian}

\section{Teknik Penentuan Responden}

Penentuan responden ini dilakukan secara purposive (sengaja) yang terdiri dari responden kunci dan responden umum. Pendekatan menggunakan responden sampling dan data spasial untuk melihat luas pemukiman warga dan lahan pekebunan petani.

\section{Teknik Pengumpulan Data}

Data yang dikumpulkan dalam peneltian ini terbagi atas 2 (dua) bagian, yaitu data primer dan data sekunder. Data Primer meliputi:

1. Observasi lapangan atau pengamatan secara langsung mengenai jasa ekosistem penyedia air dan pangan di kampung Somi dan Wasai (berbasis citra satelit).

2. Mendata luasan setiap jenis penggunaan lahan oleh masyarakat sebagai lahan pertanian (berbasis citra satelit).

3. Mendata jenis bahan pangan yang terdapat disetiap lahan pertanian pada kampung Somi dan Wasai (wawancara). Wawacara dilakukan kepada masyarakat bila lokasi pertanian (kebun) masyarakat berjarak $>1 / 5$ $\mathrm{km}$, sebaliknya jika berjarak $<1 / 5 \mathrm{Km}$, maka akan dilakukan pengukuran langsung.

Sementara data sekunder yang dikumpulkan antara lain eadaan umum lokasi penelitian meliputi topografi, iklim, tanah, jumlah penduduk sarana dan prasarana serta data dari instasi- instansi terkait dan beberapa pustaka yang dapat menunjang penelitian ini.

\section{Pengolahan Data}

Daya dukung jasa ekosistem air diukur berdasarkan perbandingan ketersediaan dan kebutuhan air, sedangkan daya dukung ekosistem pangan diukur berdasarkan ketersediaan dan kebutuhan lahan pertanian. Kedua daya dukung tersebut dihitung dengan pendekatan yang tertuang pada Peraturan Menteri Lingkungan Hidup (Per-Men) Negara Lingkungan Hidup No. 17 Tahun 2009 tentang Pedoman Daya Dukung Lingkungan Hidup Dalam Penataan Ruang Wilayah.

1. Pendekatan penghitungan penentuan daya dukung air dilakukan dengan membandingkan ketersediaan dan kebutuhan air, dapat dilihat pada Gambar 1 .

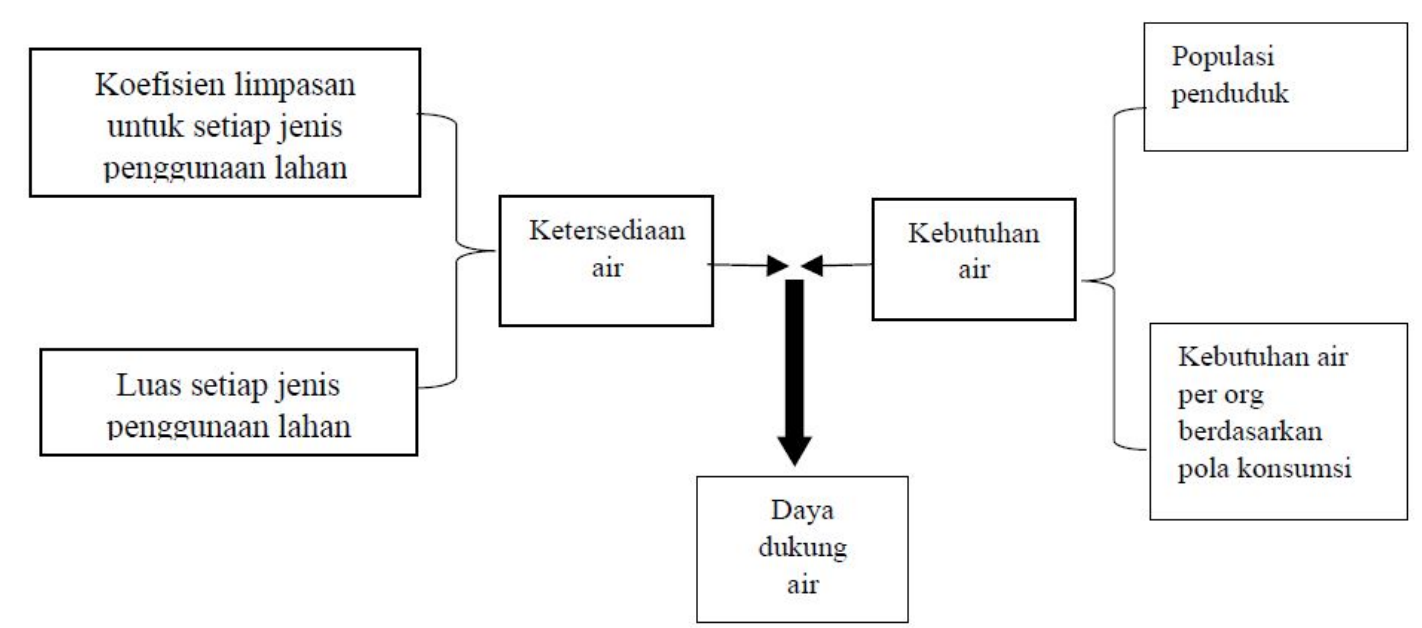

Gambar 1. Alur perhitungan penentuan daya dukung air

Ketersediaan air ditentukan dengan menggunakan metode koefisien limpasan berdasarkan informasi penggunaan lahan. Sementara itu kebutuhan dihitung dari hasil 
konversi terhadap kebutuhan hidup yang layak. Perhitungan dengan menggunakan metode koefisien limpasan yang dimodifikasi dari metode rasional.

Rumus:

$$
\begin{aligned}
& C=\Sigma(\text { cix Ai) } / \Sigma A i \\
& R=\Sigma R i / m \\
& S A=10 \times C \times R \times A
\end{aligned}
$$

Keterangan:

$\begin{array}{lll}\mathrm{SA} & =\text { Ketersediaan air }\left(\mathrm{m}^{3} / \text { tahun }\right) \\ \mathrm{C} & =\text { Koefisien limpasan tertimbang } \\ \mathrm{Ci} & =\text { Koefisien limpasan } \\ & \text { penggunaan lahan } & \end{array}$

$\mathrm{Ai}=$ Luas penggunaan lahan $\mathrm{i}$ (ha) dari data BPS atau daerah dalam angka, atau dari data Badan Pertanahan Nasional (BPN)

$\mathrm{R}$ = Rata-rata aljabar curah hujan tahunan wilayah (mm/tahunan) dari data BPS atau BMG atau dinas terkait setempat.

$\mathrm{Ri}=$ Curah hujan tahunan pada stasiun $\mathrm{i}$

$\mathrm{m}=$ Jumlah stasiun pengamatan curah hujan

A = Luas wilayah (ha)

$10=$ Faktor konversi dari $\mathrm{mm}$ ha menjadi $\mathrm{m}^{3}$.

Tabel 1. Koefisien limpasan air tertimbang berdasarkan deskripsi permukaan dan koefisien impasan

\begin{tabular}{llc} 
No. & \multicolumn{1}{c}{ Deskripsi permukaan } & $\begin{array}{c}\text { Koefisien impa } \\
\text { (ci) }\end{array}$ \\
\hline 1. & Jalan, aspal, atap genteng & $0,7-0,9$ \\
2 & Kawasan industry & $0,5-0,9$ \\
3 & Pemukiman multi unit, & $0,6-0,7$ \\
& pertokoan & \\
4 & Kompleks perumahan & $0,4-0,6$ \\
5 & Villa & $0,3-0,5$ \\
6 & Taman, pemakaman & $0,1-0,3$ \\
7 & Pekarangan tanah berat: & \\
& a. $>7 \%$ & $0,25-0,5$ \\
& b. $2-7 \%$ & $0,18-0,22$ \\
& c. $<2 \%$ & $0,13-0,17$
\end{tabular}

8 Pekarangan tanah ringan:
a. $>7 \%$
$0,15-0,2$
b. $2-7 \%$
$0,10-0,22$
c. $<2 \%$
$0,05-0,10$
Lahan berat $\quad 0,40$
10 Padang rumput $\quad 0,35$
11 Lahan budidaya pertanian $\quad 0,30$
12 Hutan produksi 0,18

$\sum$ (ai) $\sum(\mathrm{ci} \times \mathrm{ai})$

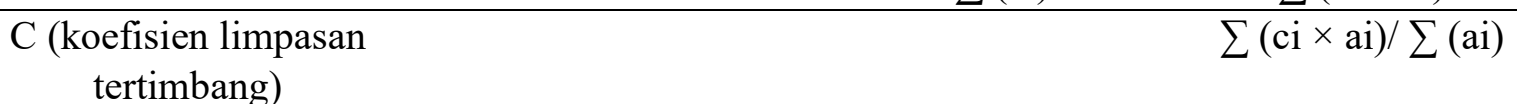

Sumber: Permen Negara lingkungan Hidup No 17 Tahun 2009 
Kemudian untuk menghitung kebutuhan (demand) air dengan rumus :

Rumus: $\mathrm{D}_{\mathrm{A}}=\mathrm{N} \times$ KHLA

Keterangan :

$\mathrm{D}_{\mathrm{A}} \quad=$ Total kebutuhan air $\left(\mathrm{m}^{3} /\right.$ tahun $)$

$\mathrm{N} \quad=$ Jumlah penduduk (orang)

$\mathrm{N}=$ Jumlah penduduk (orang)

$\mathrm{KLH}_{\mathrm{A}}=160 \mathrm{~m}^{3}$ air/kapita/ tahun,

$=2 \times 800 \mathrm{~m}^{3}$ air $/$ kapita/tahun, dimana: $800 \quad \mathrm{~m}^{3} /$ kapita/tahun merupakan kebutuhan air untuk keperluan domestik dan untuk kebutuhan air dan untuk menghasilkan pangan.

Selanjutnya penentuan status daya dukung air diperoleh dari perbandingan antara ketersediaan air $\left(\mathrm{S}_{\mathrm{A}}\right)$ dan kebutuhan air $\left(\mathrm{D}_{\mathrm{A}}\right)$. Bila $\mathrm{S}_{\mathrm{A}}>\mathrm{D}_{\mathrm{A}}$, maka daya dukung air dinyatakan surplus. Bila $\mathrm{S}_{\mathrm{A}}<\mathrm{D}_{\mathrm{A}}$, daya dukung air dinyatakan defisit atau terlampau. Penentuan daya dukung lahan dilakukan dengan membandingkan ketersediaan dan kebutuhan lahan seperti digambarkan dalam diagram di bawah ini.

2. Untuk menetukan ketersediaan lahan pertanian dalam penelitian tidak menggunakan perhitungan dalam Peraturan Menteri Lingkungan Hidup (Per-Men) Negara Lingkungan Hidup No. 17 Tahun 2009, tetapi didasarkan pada data sekunder luas kelas tutupan lahan pertanian masyarakat dan lahan yang dapat dimanfaatkan masyarakat untukkegiatan pertanian. Kebutuhan lahan pertanian dihitung berdasarkan kebutuhan hidup layak.

DL $=$ Total kebutuhan lahan setara

beras (ha)

$\mathrm{N} \quad=$ Jumlah penduduk (orang)

KHLL = Luas lahan yang dibutuhkan untuk kebutuhan hidup layak per penduduk. Luas lahan yang dibutuhkan untuk kebutuhan hidup layak per penduduk merupakan kebutuhan hidup layak per penduduk dibagi produktifitas beras/komoditas pertanian lokal. Kebutuhan hidup layak per penduduk diasumsikan sebesar 1 ton setara beras/kapita/ tahun.

Selanjutnya untuk penentuan status daya dukung lahan pertanian diperoleh dari pembandingan antara ketersediaan lahan (SL) dan kebutuhan lahan (DL). Bila SL > DL, daya dukung lahan dinyatakan surplus. Bila SL < DL, daya dukung lahan dinyatakan defisit atau terlampaui.

\section{Analisis Data}

Data yang telah diperoleh dari penelitian ini dianalisis secara deskriptif dan disajikan dalam bentuk tabel dan gambar/foto. Analisis dilakukan untuk mengetahui berapa besar kawasan hutan pendidikan tuwanwowi yang mampu menyediakan sumber air dan pangan untuk menunjang masyarakat disekitar kawasan hutan Tuwanwowi.

\section{HASIL DAN PEMBAHASAN}

\section{Sejarah Kampung Somi dan Kampung Wasay}

Kampung Somi merupakan kampung tua yang dibangun oleh masyarakat asli suku Hatam yang berimigrasi dari Pegunungan Arfak. Kampung Somi ditetapkan berdasarkan surat keputusan kampung tahun 2000. Pada awalnya kelompok etnis penduduk yang mendiami kampung ini cukup heterogen dari beberapa suku asli Papua seperti Suku Biak, Jayapura, merauke dan suku bukan Papua antara lain suku Toraja, Timor, Bugis, Makassar, Jawa dan Manado. Namun dalam perkembangan hingga saat ini masyarakat yang bertahan hanya penduduk asli Suku Hatam. Kebanyakan penduduk pindah dari kampung Somi karena alasan kesulitan air.

Sedangkan Kampung Wasay menjadi kampung definitif pada tahun 1995 bersamaan dengan pembangunan rumah untuk pegawai pensiunan di lingkup Kabupaten Manokwari, 
sehingga penduduknya cenderung heterogen. Masyarakat kampung Wasay menyebut Kampung Wasay sebagai "kampung nusantara" karena sebaran penduduk meliputi banyak suku di Indonesia. Menurut penuturan tua marga Mansim Bapak Nathaniel Mansim, Kampung Wasay adalah wilayah ulayat marga Mansim Boray. Sehingga saat ini yang menjadi kepala kampung di Kampung Wasay adalah marga pemilik ulayat.

\section{Demografi/Kependudukan}

Luas kampung Somi 52, $56 \mathrm{~km} 2$ dan berkontribusi terhadap luas distrik sebesar $13,47 \%$ dan luas kampung Wasai 30 hektar dengan pembagian lokasi pemukiman sebesar 15 hektar dan untuk pekarangan (Tim KKN Unipa 2020). Jumlah rumah tangga di kampung Somi adalah $21 \mathrm{kk}$ atau sekitar 86 jiwa dengan laju pertumbuhan penduduk $1,94 \%$ per tahun, distribusi penduduk 0,65 dan kepadatan penduduk 2,00 per $\mathrm{km}^{2}$. Sedangkan jumlah penduduk yang mendiami kampung Wasai berjumlah 300 kepalah keluarga (KK) dari awal berdirinya kampung Wasai namun banyak warga yang tidak menetap dikampung hingga sahat ini. Berdasarkan hasil sensus yang dilakukan oleh Tim KKN kampung Wasai tahun 2020 sebanyak $58 \mathrm{KK}$ dengan jumlah total penduduk 112 orang yang mendiami kampung Wasai. Tingkat sebaran umur masyarak yang terdapat di kampung Somi terdiri dari anak - anak, remaja dan orang dewasa. Demikian juga dengan tingkat sebaran umur masyarakat yang berada dikampung Wasai. Tingkat pendidikan masyarakat kampung somi terdiri dari lulusan sekolah dasar (SD), sekolah menenga pertama (SMP) dan sekolah menenga atas (SMA).

Pada masyarakat kampung Wasai tingkat Pendidikan masyarakat mulai dari sekolah dasar sampai dengan perguruan tinggi. Jenis pekerjaan sehari - hari masyarakat kampung
Somi adalah bertani berjualan ke pasar dan berburu. Perkerjaan sehari-hari masyarakat kampung Wasai Bertani, berburuh, kuli bangunan, wiraswasta dan sebagian pegawai negeri sipil (PNS).

\section{Luas Tutupan Hutan dan Lahan Kawasan Hutan Tuwanwowi}

Peta tutupan lahan merupakan bagian dari langkah pembuatan peta daya dukung lingkungan hidup. Peta tutupan lahan merupakan salah satu proxy (perkiraan) yang harus ada sebagai dasar penyusunan daya dukung lingkungan hidup (Santoso 2020). Luas tutupan hutan di kawasan hutan Tuwanwowi didominasi oleh hutan lahan kering primer dengan proporsi seluasa $77,49 \%$ disusul hutan lahan kering sekunder $(17,27 \%)$. Hal ini menunjukkan bahwa hutan di wilayah sebagian besar merupakan hutan alam primer yang masih tertutup rapat. Hasil tumpang susun (overlay) peta menunjukkan bahwa terdapat 8 tipe tutupan lahan di kawasan hutan Tuwanwowi didominasi oleh tipe tutupan lahan hutan lahan kering primer yang merupakan salah satu potensi pengembangan kawasan ini, sebagaimana terlihat pada tabel 2 .

\section{Daya Dukung Jasa Ekosistem Penyedia Air Di Kawasan Hutan Tuwanwowi}

Daya dukung ketersedian air ketersediaan air ditentukan dengan menggunakan metode koefisien limpasan berdasarkan informasi data curah hujan tahunan. Sementara itu kebutuhan air dihitung dari hasil konversi terhadap kebutuhan hidup layak.

\section{Potensi Ketersediaan air Permukaan}

Ketersediaan air di kawasan hutan Tuwanwowi yang dapat mendukung kebutuhan masyarakat sekitar dipengaruhi oleh koefisien limpasan penggunaan lahan, rata-rata aljabar curah hujan tahunan wilayah (mm/tahunan), dan luas wilayah atau kawasan hutan tersebut. 
Tabel 2. Kondisi tutupan lahan kawasan hutan Tuwanwowi

Kelas tutupan $\quad$ Luas (Ha) $\quad$ Persen (\%)

\begin{tabular}{lcc}
\hline Hutan lahan kering primer & $7.037,8$ & 77.49 \\
Hutan lahan kering sekunder & $1.568,7$ & 17.27 \\
Pemukiman & 8.7 & 0.095 \\
Perkebunan & 247.3 & 2.723 \\
Pertanian lahan kering & - & - \\
Campur semak & 0,1 & 0.0006 \\
Semak/belukar & 219.3 & 2.414 \\
Jumlah & $9,081.7$ & 100 \\
\hline
\end{tabular}

Koefisien limpasan tertimbang dipengaruhi oleh koefisien limpasan penggunaan lahan dan luas penggunaan lahan. Koefisien limpasan penggunaan lahan didasarkan pada tabel koefesien limpasan baku sesuai Per-Men LH Nomor 17 tahun 2009 tentang pedoman penentuan daya dukung lingkungan hidup dalam penataan ruang wilayah. Sedangkan data luasan penggunaan lahan diperoleh didasarkan pada informasi tutupan lahan tahun 2019 seperti pada tabel 3.

Tabel 3. Koefisien limpasan tertimbang di kawasan hutan Tuwanwowi

\begin{tabular}{|c|c|c|c|c|}
\hline No. & Deskripsi permukaan & $\begin{array}{c}\text { Koefisien } \\
\text { limpasan (ci) }\end{array}$ & $\begin{array}{c}\text { Luas } \\
\text { lahan (ai) }\end{array}$ & $(\mathrm{ci} \times$ ai $)$ \\
\hline 1 & $\begin{array}{l}\text { Pemukiman (kompleks } \\
\text { perumahan) }\end{array}$ & $0,4-0,6$ & 8,66 & 3,46 \\
\hline 2 & $\begin{array}{l}\text { Semak/belukar (padang } \\
\text { rumput) }\end{array}$ & 0,35 & 219,27 & 76,74 \\
\hline 3 & $\begin{array}{l}\text { Perkebunan dan pertanian } \\
\text { lahan kering (lahan } \\
\text { budidaya pertanian) }\end{array}$ & 0,3 & 247,31 & 74,19 \\
\hline \multirow[t]{2}{*}{4} & $\begin{array}{l}\text { Hutan lahan kering } \\
\text { primer dan hutan lahan } \\
\text { kering sekunder (hutan } \\
\text { produksi) }\end{array}$ & 0,18 & $8.606,42$ & $1.549,16$ \\
\hline & Jumlah $(\Sigma)$ & & $9.081,66$ & $1.703,56$ \\
\hline
\end{tabular}

Dari data tabel 3 menunjukkan bahwa limpasan koefisien dan luas lahan yang terbesar adalah pada lahan hutan primer dan hutan sekunder dengan nilai sebesar $1.549,16$ ha disusul semak/belukar (padang rumput), dan yang terkecil adalah pemukiman. Selanjutnya berdasarkan hasil tersebut ditentukan besarnya koefisien tertimbang ( $\mathrm{C}$ tertimbang) sebagai berikut :

$\mathrm{C}$ tertimbang Tuwanwowi $=\mathrm{C}$ area $\times$ luas area/luas area $=1.703,56 / 9.081,66 / 9.081,66=$ 0,187

Berdasarkan hasil perhitungan $\mathrm{C}$ tertimbang diperoleh nilai 0,187 , artinya air hujan yang 
jatuh hanya $18,7 \%$ yang menjadi air permukaan dan 91,3\% merupakan air yang mengalami infiltrasi dan masuk menjadi air bawah tanah. Nilai ini jauh lebih rendah dibandingkan dengan nilai koefisien tertimbang di beberapa lokasi seperti Ubud dan Kecamatan Gianjar Kabupaten Gianjar Bali serta kecamatan Tujuh Belas Kabupaten Bangka yang dimana nilai koefisien tertimbanga sebesar 0,44 dan 0,45 serta 0,308 (Pramesty dkk. 2013; Napitu dkk. 2018). Fakta diatas membuktikan bahwa kawasan hutan dan vegetasi penutup tanah di sekitar hutan Tuwanwowi masih relatif baik. Air permukaan adalah air yang terkumpul di atas tanah atau di mata air, sungai danau, lahan basah, atau laut. Air permukaan secara alami terisi melalui presipitasi dan secara alami berkurang melalui penguapan dan rembesan ke bawah permukaan sehingga menjadi air bawah tanah. Air permukaan merupakan sumber terbesar untuk air bersih.

Selanjutnya dihitung rata-rata aljabar curah hujan tahun wilayah hutan Tuwanwowi menggunakan data curah hujan tahunan kabupaten Manokwari yang diperoleh dari BMKG stasiun Manokwari. Rata-rata curah hujan tahunan diperoleh dari penjumlahan data curah hujan 5 tahun terakhir (2015-2019). Dari data curah hujan dapat disimpulkan bahwa total curah hujan berdasarkan data 5 tahun terakhir mencapai rata - rata 2.863,02. Dengan demikian nilai $\mathrm{R}$ kawasan hutan Tuwanwowi sebesar 2.863,02 mm/tahun. Berdasarkan nilai $\mathrm{R}$ dan A yang telah dihitung maka dapat dihitung nilai ketersediaan air (SA).

SA

$$
=10 \times \mathrm{R} \times \mathrm{C} \times \mathrm{A}
$$

SA Tuwanwowi $\quad=10 \times 2.863,02 \times 0,187$ $\times 9.081,66$

$$
=48.621 .821,78 \mathrm{~m}^{3} / \text { tahun }
$$

Secara kuantitatif jumlah potensi ketersedian air pemukaan di Tuwanwowi terlihat besar, namun penduduk kampung Somi mengalami kesulitan mendapat air bersih, hal ini disebabkan kondisi topografi terjal dan kondisi bahan induk batuan penyusun yang lebih dominan bantuan karang/karts. Pada kawasan kart terdapat rongga-rongga hasil pelarutan di permukaan bukit karst berperan sebagai simpanan utama air tanah karst. Zona ini disebut zona epikarst yaitu lapisan dimana terdapat konsentrasi air hasil infiltrasi air hujan (Adji dan Nugroho 2010). Epikarstic zone atau subcutaneous zone adalah zone teratas yang tersingkap dari batuan karst yang memiliki permeabilitas dan porositas karena proses pelebaran celah pada zona ini merupakan yang paling tinggi dibanding lapisan-lapisan yang lain, dengan demikian dapat berperan sebagai media penyimpanan yang baik (Adji dan Nugroho 2010). Namun hal itu tidak terjadi karena sangat sedikit atau vegetasi yang tumbuh sangat jarang di kampung Somi karena itu tindakan revegatsi di sekitar kampung dan wilayah-wilayah sekitar perlu dilakukan. Konservasi epikarst dapat dilakukan dengan menanam rumput di permukaan. Rumput berperan sebagai penyaring sehingga hanya sedimen saja yang mengendap pada epikarst. Selain itu apabila akan membuat teras untuk tegalan, diupayakan tidak sampai memotong zona epikarst ini karena akan mengurangi kapasitas simpanan air tanah (Ashari 2012).

\section{Kebutuhan (Demand) Air Masyarakat}

Pola konsumsi kebutuhan air domestik (MCK dan lainnya) paling banyak berasal dari air sungai dan air hujan. Ada juga sebagia penduduk kampung Wasay yang memanfaatkan air tangki dengan mengkonsumsi air sebesar 80 liter/orang/hari. Sumber kebutuhan air paling banyak dari air hujan, hanya pada musim kemarau kebanyakan memanfaatkan air sungai. Pola konsumsi kebutuhan air minum sehari-hari di kampung Somi dan Wasay sebagian besar berasal dari air kemasan, tetapi masih ada yang mengkonsumsi air minum dari air hujan dan sungai, atau dari dua sumber sekaligus. Perhitungan kebutuhan air domestik 
berdasarkan perhitungan standar kebutuhan air oleh Direktorat Jendral Cipta Karya (2016) sebagai berikut:

Diketahui:

$\mathrm{g}(\mathrm{r}) \quad=80$ liter/orang/hari

$\mathrm{P}(\mathrm{r})$ Somi $=86$ jiwa

$\mathrm{P}(\mathrm{r})$ Wasay $=112$ jiwa

$\mathrm{Q}$ air minum $(\mathrm{QA})=2$ liter/orang/hari atau 730

liter/orang/tahun

Keterangan g(r) : Konsumsi air daerah pedesaan (liter/orang/hari)

$\mathrm{p}(\mathrm{r}) \quad:$ Jumlah penduduk pedesaan

Q : Kebutuhan air

$\mathrm{Q}$ (DMI) Somi $=365$ hari $\times\{\mathrm{g}(\mathrm{r}) / 1000 \times$

$\mathrm{P}(\mathrm{r})\}+\mathrm{QA}=365 \times\{80 / 1000 \times 86\}+730=$

$3.241,2 \mathrm{~m}^{3} /$ tahun

$\mathrm{Q}(\mathrm{DMI})$ Wasay $=365$ hari $\times\{\mathrm{g}(\mathrm{r}) / 1000 \times$

$\mathrm{P}(\mathrm{r})\}+\mathrm{QA}$

$$
\begin{aligned}
& =365 \times\{80 / 1000 \times 112\}+730 \\
& =4.000,4 \mathrm{~m}^{3} / \text { tahun }
\end{aligned}
$$

$\mathrm{Q}$ (DMI) Tuwanwowi $=3.241,2+4.000,4=$ $7.241,8 \mathrm{~m}^{3} /$ tahun

Kebutuhan air masyarakat di kampung Wasay lebih besar $\left(4.000,4 \mathrm{~m}^{3} /\right.$ tahun $)$ dari pada kampung Somi $\left(3.2141,2 \mathrm{~m}^{3} /\right.$ tahun). Hal ini berkaitan dengan jumlah penduduk dan sumber air yang tersedia di kedua kampung tersebut, dimana sumber air berupa sungai terletak di lokasi yang muda diakses masyarakat kampung Wasay dibanding kampung Somi.
Masyarakat di kedua kampung tidak hanya mengkonsumsi air dari satu sumber saja, melainkan dua sumber sekaligus yakni dari air hujan dan sungai. Alasan masyarakat mengkonsumsi air dari dua sumber adalah sebagai tindakan antisipasi apabila suatu waktu tidak terjadi hujan atau sebaliknya air sungai menjadi kering. Sebagian besar masyarakat kampung Somi dan Wasay mengkonsumsi minum dari air kemasan dengan alasan lebih praktis, higienis, dan aman dikonsumsi. Masyarakat di kampung Wasay juga mengkonsumsi air dari penjualan tangki dengan jumlah 1.000 liter sampai 2.500 liter sekali pengisian. Harga pembeliaan air berkisar dari Rp. 100.000 sampai Rp. 250.000 per tangki. Untuk masyarakat Somi sulit mendapat air tangki karena wilayah kampung sulit akses jalan yang dapat dilalui mobil ukuran truk.

\section{Penentuan Status Daya Dukung Air}

Status daya dukung diperoleh perbandingan antara ketersediaan air (SA) $\mathrm{m}^{3} /$ tahun dan total kebutuhan air $\mathrm{m}^{3} /$ tahun (DA). Apabila SA > DA, maka daya dukung air dinyatakan surplus. Apabilah SA $<$ DA, maka daya dukung air dinyatakan deficit atau terlampaui. Dari hasil analisis tersebut maka dapat diketahui bahwa ketersediaan air di kawasan Tuwanwowi sangat melimpah.

Tabel 4. Status daya dukung sumberdaya air di kawasan Tuwanwowi

\begin{tabular}{lccc}
\hline \multicolumn{1}{c}{ Faktor } & Rumus & Nilai & Satuan \\
\hline Ketersediaan Air & S $_{A}$ & $48.621 .821,78$ & $\mathrm{~m}^{3} /$ tahun \\
Kebutuhan Air & $\mathrm{D}_{\mathrm{A}}$ & $7.241,8$ & jiwa.m \\
Status daya dukung & Surplus jika $\mathbf{S}_{\mathbf{A}}>\mathbf{D}_{\mathbf{A}}$ & & Surplus \\
air & Defisit jika $\mathbf{S}_{\mathbf{A}}>\mathbf{D}_{\mathbf{A}}$ & & \\
\hline
\end{tabular}

\section{Daya Dukung Penyedia Pangan}

Kawasan hutan Tuwanwowi kabupaten Manokwari memiliki karakteristik lahan tersendiri, mengacu kepada kawasan konservasi dan hutan pendidikan. Masing-masing bentuk atau tipe lahan tersebut memiliki ciri khas yang berbeda termasuk dalam lahan penyediaan bahan pangan bagi manusia (Lekitoo et al. 
2017). Berdasarkan hasil penelitian yang dilakukan dapat dikatakan bahwa jasa ekosistem untuk penyediaan pangan di daerah Tuwanwowi diantaranya tepat pada kampung Somi dan Wasai sangat mendukung hasil pertanian masyarakat sekitar. Ketersediaan pangan yang terdapat di kampung Somi dan Wasai sangat merata pada seluruh luasan wilayah, sebaran ditiap kampung untuk penyedia pangan sangat mendukung.

Dengan adanya penelitian ini dapat dikatakan bahwa hasil pangan yang terdapat di kampung somi dan Wasai dengan melihat beberapa hasil pertanian masyarakat dan juga luasan lahan penyedia pangan perkampung sangat bervariasi dengan ukuran yang tidak menetap. Sumber hasil pertanian atau pangan spesifik lokal yang terdapat di kampung Somi dan Wasai pada kawasan hutan Tuwanwowi Manokwari Papua Barat terdiri dari hasil pertanian, terutama komoditas pangan seperti singkong, keladi, ubi jalar, pisang dan beberapa jenis sayuran yang menyebar luas dimasyarakat diantaranya kacang panjang, kangkung, ketimun, pare, papaya, jagung dan rica (Sonbait et al. 2018). Komoditas tersebut telah menjadi sumber bahan pangan alternatif yang dapat menjamin masyarakat lokal maupun masyarakat bukan Papua. Pangan lokal yang di produksi dengan tujuan menghidupkan ekonomi masyarakat dan juga sebagai bahan penggati beras yang selama ini dikonsumsi masyarakat (Cabuy et al. 2012; Asmuruf dkk. 2018; Kambuaya dkk. 2019). Hasil pertanian ini ditanam pada lahan kering primer yang luasnya 0,1 ha dan Sebagian ditanam di lahan hutan sekunder yang luasnya $1.568,8$ ha. Sehingga lahan yang kemungkinan dapat dikelola oleh masyarakat di kedua kampung untuk tanaman pangan seluas $1.568,8$ ha.

Selanjutnya dilakukan perhitungan kebutuhan lahan untuk kegiatan pertanian yang mendukung ketahanan pangan bagi masyarakat. Pendekatan yang digunakan adalah dengan produktifitas lahan untuk singkong dan ubi jalar Perhitungan kebutuhan lahan untuk hidup layak menggunakan rumus seperti tertuang dalam Permen LH N0. 17, 2009. Luas lahan yang dibutuhkan untuk kebutuhan hidup layak per penduduk merupakan kebutuhan hidup layak per penduduk dibagi produktivitas singkong dan ubi jalar lokal. Kebutuhan hidup layak per penduduk diasumsikan sebesar 1 ton setara singkong atau ubi jalar/kapita/tahun. Sedangkan produktifitas singkong dan ubi jalar Manokwari berdasarkan data BPS masing masing 11,213 ton dan 10,282 ton. Sehingga untuk mendapatkan alokasi kebutuhan lahan bagi kegiatan budidaya singkong dan ubi jalar dihitung sebagai berikut:

KHLL = Kebutuhan hidup layak per penduduk/produktifitas singkong atau ubi jalar lokal

$\mathrm{KHLL}=1$ ton singkong $/ 11,213$ ton $/$ ha/tahun $=$ $0,089 \mathrm{ha} /$ orang

KHLL $=1$ ton ubi jalar/10,282 ton/ha/tahun $=$ 0,09 ha/orang

Total singkong + ubi $=0,089+0,09=0,179$ ha/orang

Dengan demikian kebutuhan lahan untuk hidup layak di kampung Somi dan Wasay adalah 0,179 ha/orang. Kebutuhan lahan diperoleh dengan cara mengalikan jumlah penduduk $(\mathrm{N})$ dengan kebutuhan lahan untuk hidup layak (KHLL). Jumlah penduduk berdasarkan data monografi kampung untuk Somi dan Wasai adalah 198 orang, sedangkan kebutuhan lahan untuk hidup layak (KHLL) berdasarkan hasil perhitungan di atas adalah 0,179 ha/orang. Perhitungan kebutuhan lahan (DL) mengacu seperti pada rumus persamaan berikut:

$$
\begin{aligned}
& \mathrm{DL}=198 \times 0,179 \\
& \mathrm{DL}=35,442 \mathrm{ha},
\end{aligned}
$$

Dengan demikian diperoleh kebutuhan lahan (DL) adalah 35,442 ha. 


\section{Status Daya Dukung Lahan}

Penentuan status daya dukung lahan diperoleh dari pembandingan antara ketersediaan lahan (SL) dan kebutuhan lahan (DL).

Bila SL > DL, daya dukung lahan dinyatakan surplus.

Bila SL $<$ DL, daya dukung lahan dinyatakan defisit atau terlampaui.

Berdasarkan hasil perhitungan yang diperoleh di atas ketersediaan lahan (SL) $1.568,8$ ha sedangkan nilai kebutuhan lahan (DL) adalah 35,442 ha. Dengan demikian, diperoleh nilai $\mathrm{SL}<\mathrm{DL}$ dan daya dukung lahan dinyatakan surplus atau melimpah. Dari hasil perhitungan daya dukung dengan menggunakan konsep perhitungan sesuai Peraturan Menteri Lingkungan Hidup No. 17 Tahun 2009, kawasan hutan Tuwanwowi mempunyai status daya dukung lahan yang surplus terhadap penduduk yang tinggal disekitar. Dapat dikatakan bahwa kebutuhan akan lahan di kampung Somi dan Wasai lebih kecil dari ketersediaan lahan.

Ketersediaan lahan adalalah lahan yang tersisa untuk digunakan sebagai lahan pertanian/perkebunan/perikanan darat setelah semua lahan itu dimaksimalkan pemanfaatannya. Ketersediaan lahan ditentukan berdasarkan produksi aktual setempat dari semua komoditas yang ada di wilayah tersebut. Kebutuhan lahan adalah kebutuhan hidup minimum. Kebutuhan lahan tercemin pada kemungkinan penggunaan lahan untuk memenuhi kebutuhan tertentu.

Mantra (1986), mengatakan bahwa penurunan daya dukung lahan dipengaruhi oleh jumlah penduduk yang terus meningkat, luas lahan yang semakin berkurang, persentase jumlah petani dan luas lahan yang diperlukan untuk hidup layak, dan jenis komoditas yang ada di wilayah setempat. Daya dukung lahan yang surplus sangat dipengaruhi oleh jumlah penduduk. Penduduk Somi dan Wasai saat ini masih sangat sedikit namun demikian ke depan tiap tahunnya terus meningkat. Penduduk yang terus bertambah menyebabkan tingkat pertumbuhan tersebut jauh lebih tinggi dibandingkan tingkat pertambahan luas lahan untuk tanaman pangan. Faktor perilaku masyarakat terhadap lahan mempengaruhi daya dukung lahan itu sendiri. Di lihat dalam hal kependudukan meliputi kepadatan penduduk, migrasi penduduk komposisi penduduk seperti: (jenis kelamin, pendidikan, struktur umur dan mata pencaharian) serta penguasaan/pemilikan tanah. Penurunan kualitas sumber daya lahan akibat semakin kompleksnya permintaan kebutuhan pemilikan lahan atau pengolahan lahan mengakibatkan terjadinya penurunan daya dukung lahan.

Tekanan penduduk banyak terjadi di wilayah yang mempunyai kemampuan lahan rendah. Faktor-faktor yang mempengaruhi tekanan penduduk adalah struktur pekerjaan, kemampuan lahan dan kepadatan agraris. Adanya pertambahan penduduk akan memerlukan pertambahan kebutuhan sandang, pangan dan papan. Ketidakseimbangan pertambahan penduduk dengan pertambahan kebutuhan sangat mempengaruhi keadaan lingkungan hidupnya, yaitu lingkungan akan dieksploitasi besar-besaran untuk memenuhi kebutuhan hidup. Akibatnya daya dukung lingkungan akan berkurang dan terjadi kerusakan lingkungan yang serius. Pertumbuhan penduduk yang tinggi akan menimbulkan berbagai dampak di antaranya adalah meningkatkan kebutuhan lahan baik untuk pemukiman, sarana infrastruktur, dan lahan pertanian (Marwa et al. 2019). Pada kenyataannya terjadi kecenderungan penyempitan lahan untuk pertanian sebagai imbas dari pembangunan fisik suatu daerah. Di sisi lain pertambahan penduduk yang terus meningkat akan memicu penurunan kapasitas daya dukung lahan dan menyebabkan daya dukung lahan menjadi defisit. 


\section{KESIMPULAN}

Berdasarkan hasil perhitungan yang diperoleh di atas ketersediaan lahan (SL) $1.568,8$ ha sedangkan nilai kebutuhan lahan (DL) adalah 35,442 ha. Dengan demikian, diperoleh nilai $\mathrm{SL}<\mathrm{DL}$ dan daya dukung lahan dinyatakan surplus atau melimpah. Dari hasil perhitungan daya dukung dengan menggunakan konsep perhitungan sesuai Peraturan Menteri Lingkungan Hidup No. 17 Tahun 2009, kawasan hutan Tuwanwowi mempunyai status daya dukung lahan yang surplus terhadap penduduk yang tinggal disekitar. Demikian dapat dikatakan juga bahwa ketersediaan air $\mathrm{S}_{\mathrm{A}}$ yang tersimpan mencapai 48.621.821,78 $\mathrm{m}^{3} /$ tahun dan kebutuhan air $\mathrm{D}_{\mathrm{A}} 7.241,8$ jiwa $\mathrm{m}^{3} /$ tahun. Dapat dikatakan bahwa kebutuhan akan lahan di kampung Somi dan Wasai lebih kecil dari ketersediaan lahan.

\section{DAFTAR PUSTAKA}

Adji dan Nugroho T. 2010. Kondisi daerah tangkapan sungai bawah tanah karst Gunung Sewu dan kemungkinan dampak lingkungannya terhadap sumberdaya air (hidrologis) karena aktivitas manusia. Seminar Pelestarian Sumberdaya Airtanah Kawasan Karst Gunungkidul. UGK BP DAS SOP.

Ashari A. 2012. Konservasi bukit karst sebagai tindakan mitigasi kekeringan di daerah tangkapan hujan sub sistem geohidrologi bribin-baron-seropan karst Gunung Sewu. Geomedia, 10 (1): 95-110.

Asmuruf F, Wanma J dan Rumatora A. 2018. Budidaya dan pemanfaatan sagu (Metroxylon sp.) oleh sub-etnis Ayamaru di kampung Sembaro distrik Ayamaru Selatan. Jurnal Kehutanan Papuasia, 4 (2): 114-127, https://doi.org/10.46703/jurnalpapuasia.Vol 4.Iss2.100.
Bratakusumah, Supriady D dan Riyadi. 2005, Perencanaan pembangunan daerah, Penerbit PT. Gramedia Pustaka Utama, Jakarta.

Cabuy RL, Marwa J, Manusawai $\mathrm{J}$ and Rahawarin YY. 2012. Non-woody plant species of Papuan island forest, a sustainable source of food for the local communities. Indian Journal of Traditional Knowledge, 11 (4): 586-592.

Direktorat Jenderal Cipta Karya. 2016. Rencana strategis kementerian pekerjaan umum dan perumahan rakyat tahun 2015-2019. www.ciptakarya.pu.go.id Diakses pada 05 Maret 2017.

Kambuaya F, Beljai M dan Wanggai CB. 2019. Pemanfaatan tanah hutan sebagai alternatif pengobatan tradisional masyarakat kampung Mapura kabupaten Maybrat. Jurnal Kehutanan Papuasia, 5 (2): 142-152, https://doi.org/10.46703/jurnalpapuasia.Vol5 .Iss2.147.

Lekitoo K, Peday HFZ, Panambe N, Cabuy RL. 2017. Ecological and ethnobotanical facet of 'Kelapa Hutan' (Pandanus spp.) and perspectives towards its existence and benefit. International Journal of Botany. 13: 103-114.

Mantra IB. 1986. Pengantar studi demografi, Nur Cahaya, Yogyakarta.

Marwa J, Sardjono MA, Ruchaemi A, Devung S dan Cabuy RL. 2019. Benefit sharing schema from the forest: Identifying potential distributions to customary communities in Teluk Bintuni district, Indonesia. Acta Universitatis Agriculturae Et Silviculturae Mendelianae Brunensis, 67 (4): 963-972. https://doi.org/10.11118/actaun2019670409 63.

Napitu DT, Wiyanti dan Diara IW. 2018. Analisis daya dukung air untuk kebutuhan air bersih domestik di kecamatan Gianyar dan Ubud, Kabupaten Gianyar. Agroekoteknologi Tropika, 7 (2): 154-163. 
Peraturan Menteri Negara Lingkungan Hidup. 2009. Permen LH Nomor 17 Tahun 2009. Kementerian Lingkungan Hidup Republik Indonesia.

Pramesty AR, Nirmala A dan Aspan A. 2013. Perhitungan daya dukung lingkungan berdasarkan ketersediaan air dan produktivitas lahan di kecamatan Tujuh Belas kabupaten Bengkayang. Kalimantan Barat.

https://media.neliti.com/media/publications/ 191063-ID-perhitungan-dayadukunglingkungan-berda.pdf. [Diakses 8 oktober 2020].

Santoso KDH, Hudawan D, Prasetya DJ dan Saputra DR. 2020. Analisis daya dukung lingkungan hidup berbasis jasa ekosistem penyediaan air bersih di Pulau Karimunjawa. Jurnal Ilmu Lingkung, 18 (2): 290- 296.

Shiva. 2002 Satatus daya dukug lingkungan dengan pendekatan air menunjukan suatu kondisi ketersediaan air dengan kebutuhan yang ada.

Soemarwoto. 1983 Daya dukung lahan merupakan kemampuan suatu lingkungan untuk mendukung lingkungan kehidupan.

Sonbait LY, Warmetan H, Manik H dan Cabuy RL. 2018. Inter-dependency of forest diversity and service towards the potency of ecotourism development in Pegunungan Arfak nature reserve. Ecology, Environment and Conservation Journal 24: 1952-1957. 